\title{
THE
}

$10-2008$

\section{When Is Antipsychotic Polypharmacy Supported by Research Evidence? Implications for QI}

Jessica L. Gören

University of Rhode Island, jgoren@challiance.org

J. Parks

Frank A. Ghinassi

Celeste G. Milton

John M. Oldham

See next page for additional authors

Follow this and additional works at: https://digitalcommons.uri.edu/php_facpubs

Terms of Use

All rights reserved under copyright.

\section{Citation/Publisher Attribution}

Goren, J. L., Parks, J. J., Ghinassi, F. A., Milton, C. G., Oldham, J. M., Hernandez, P., Chan, J., \& Hermann, R. C. (2008). When Is Antipsychotic Polypharmacy Supported by Research Evidence? Evidence for QI. Joint Commission Journal on Quality and Patient Safety, 34(10), 571-582. doi: 10.1016/

S1553-7250(08)34072-0

Available at: http://dx.doi.org/10.1016/S1553-7250(08)34072-0

This Article is brought to you for free and open access by the Pharmacy Practice at DigitalCommons@URI. It has been accepted for inclusion in Pharmacy Practice Faculty Publications by an authorized administrator of DigitalCommons@URI. For more information, please contact digitalcommons-group@uri.edu. 


\section{Authors}

Jessica L. Gören, J. Parks, Frank A. Ghinassi, Celeste G. Milton, John M. Oldham, Pablo Hernandez, Jeffrey Chan, and Richard C. Hermann

This article is available at DigitalCommons@URI: https://digitalcommons.uri.edu/php_facpubs/15 
The Joint Commission Journal on Quality and Patient Safety

\section{Performance Measures}

\section{W hen Is Antipsychotic Polypharmacy Supported by Research Evidence? I mplications for Q I}

Jessica L. Gören, Pharm.D. B.C.P.P.; Joseph J. Parks, M .D .; Frank A. G hinassi, Ph.D .; C eleste G. M ilton, M .P.H ., B.S.N., R.N .; John M . Oldham, M.D.; Pablo Hernandez, M .D .; Jeffrey Chan; Richard C. Hermann, M .D., M .S.

A ntipsychotic drugs have demonstrated efficacy and effectiveness for the treatment of schizophrenia and other psychotic disorders. ${ }^{1}$ In addition, certain traditional antipsychotics are approved by the Food and Drug Administration (FDA) for treatment of Tourette's syndrome and mania, whereas selected second-generation antipsychotics (SGAs) have additionally received approval for bipolar disorder (manic and maintenance phases) and as adjunctive treatment for treatment-resistant depression..$^{2-6}$

$\mathrm{H}$ igh rates of antipsychotic polypharmacy, defined as the concurrent use of more than one standing antipsychotic drug among patients treated with an antipsychotic, have been observed in numerous studies. ${ }^{7-28}$ Rates vary widely, depending on the population, setting, and how polypharmacy is measured. On the basis of the threshold of two or more antipsychotics, studies of acutely hospitalized patients report rates of $30 \%-40 \%, 8,9,11,12$ whereas studies of outpatient samples (across the D epartment of Veterans Affairs, M edicaid, and state mental health systems) report rates of $11 \%-35 \%,{ }^{13,14,16}$ Less information is available on concurrent use of more than two antipsychotics; one study reported that $4.6 \%$ of inpatients were on three or more antipsychotics. ${ }^{8}$ Most of these studies lack information on the degree to which use of multiple antipsychotics was clinically appropriate. M edical records typically lack the necessary documentation to make this determination, including the patient's history of previous antipsychotic trials and their outcomes or other rationales for polypharmacy. ${ }^{29-31}$

The extent of antipsychotic polypharmacy has been viewed with mounting concern, resulting in many calls for reducing its use. ${ }^{15,16,19,32-36}$ Clinically, antipsychotic polypharmacy has the potential to cause increased side effects and drug interactions. Increasing the number of medications prescribed can lead to a decline in patient adherence. ${ }^{37,38}$ Financially, the high cost of SGAs has strained state M edicaid and mental health budgets, leading some states to impose formulary restrictions limiting or delaying their use. $32,34,39,40$

M easurement-based quality improvement $(\mathrm{Q} I)$ is a method

\section{Article-at-a-Glance}

Background: Concurrent use of multiple standing antipsychotics (antipsychotic polypharmacy) is increasingly common among both inpatients and outpatients. Although this has often been cited as a potential quality-of-care problem, reviews of research evidence on antipsychotic polypharmacy have not distinguished between appropriate versus inappropriate use.

Methods: A MEDLINE search from 1966 to December 2007 was completed to identify studies comparing changes in symptoms, functioning, and/or side effects between patients treated with multiple antipsychotics and patients treated with a single antipsychotic. The studies were reviewed in two groups on the basis of whether prescribing was concordant with guideline recommendations for multiple-antipsychotic use.

Results: A review of the literature, including three randomized controlled trials, found no support for the use of antipsychotic polypharmacy in patients without an established history of treatment resistance to multiple trials of monotherapy. In patients with a history of treatment resistance to multiple monotherapy trials, limited data support antipsychotic polypharmacy, but positive outcomes were primarily found in studies of clozapine augmented with a second-generation antipsychotic.

Discussion: Research evidence is consistent with the goal of avoiding antipsychotic polypharmacy in patients who lack guideline-recommended indications for its use. The Joint Commission is implementing a core measure set for H ospital-Based Inpatient Psychiatric Services. Two of the measures address antipsychotic polypharmacy. The first measure assesses the overall rate. The second measure determines whether clinically appropriate justification has been documented supporting the use of more than one antipsychotic medication. 


\section{The Joint Commission Journal on Quality and Patient Safety}

used by hospitals and other provider organizations to assess and improve their clinical practices. Q I priorities are often established by external organizations, such as payers or accreditors, by implementing quality measures. $\mathrm{H}$ ospitals, for example, are required to report their performance on standardized core measures. External groups then use the results in one or more ways to encourage hospitals to improve, such as providing hospitals with feedback comparing their performance with peer organizations, disclosing results publicly in an effort to influence purchaser or consumer decisions, or linking financial incentives to improved performance. ${ }^{41}$

Two national measurement-based Q I initiatives are aimed at decreasing unnecessary antipsychotic polypharmacy. The $N$ ational Association of State M ental H ealth Program D irectors Research Institute has implemented a measure of antipsychotic polypharmacy rates in a number of state psychiatric hospitals. ${ }^{35}$

Effective 0 ctober 1, 2008, The Joint Commission is implementing a core measure set for Hospital-Based Inpatient Psychiatric Services; two of the measures address antipsychotic polypharmacy. The first measure assesses the hospital's overall rate. The second measure determines whether clinically appropriate justification has been documented when more than one antipsychotic is used..$^{36}$ The Joint $\mathrm{Commission}$ initiative is discussed further in the "D iscussion" section (pages 579-580).

O ne factor limiting Q I initiatives to reduce antipsychotic polypharmacy has been a lack of clarity about the research evidence regarding its use. Practice guidelines addressing multiple antipsychotic use recommend the addition of a second antipsychotic only after multiple trials of adequate duration of a single antipsychotic. ${ }^{42-44} \mathrm{H}$ owever, previous review articles evaluating antipsychotic polypharmacy ${ }^{45,46}$ have not distinguished between research studies of patients meeting this criterion and studies of patients who do not.

This article reviews studies comparing outcomes of patients receiving multiple antipsychotics with outcomes of patients receiving antipsychotic monotherapy, first, among patients with documented treatment resistance to multiple trials of a single antipsychotic, and then, among patients without an established history of treatment resistance to monotherapy.

\section{Methods}

In January 2008, we conducted a M ED LIN E search from 1966 to December 2007 to identify studies comparing changes in symptoms, functioning, and/or side effects between patients treated with multiple antipsychotics and patients treated with a single antipsychotic. The following search terms were used: antipsychotic, polypharmacy, augmentation, treatment resistance, combination, side effects, adverse reactions, quality, measure, improvement, monotherapy, outcomes, multiple antipsychotics. The reference sections of these articles and previous reviews were searched for articles not identified in the original search. Articles were restricted to the English language. Data on the study design, drugs prescribed, and changes in symptoms, functioning, and side effects were abstracted and reported.

In keeping with guideline recommendations for multiple antipsychotic use, ${ }^{42-44}$ we report findings from studies of patients with a documented history of treatment resistance (including partial response) to multiple trials of a single antipsychotic separately from studies of patients without such a history established. We examined studies within strata reflecting the rigor of their study design: randomized controlled trials (RCTs), nonrandomized controlled studies, and noncontrolled observational studies. Because of the robust number of studies with one of these designs, we excluded case reports and series without statistical analyses. M ajor limitations of each study are noted in the evidence tables; these include small sample sizes in some studies, limited matching characteristics, and short periods before follow-up assessment. Unless otherwise noted, all comparisons reported were statistically significant.

\section{Results}

Sam ples with Established Treatment Resistance TO ANTIPSYCHOTIC MONOTHERAPY

We identified six RCTs comparing antipsychotic polypharmacy to monotherapy in samples with established treatment resistance to trials of a single antipsychotic (Table 1, pages 573-575). ${ }^{47-52}$ All studies were of patients with schizophrenia or schizoaffective disorder. Two studies found that patients on multiple antipsychotics, compared with patients on a single antipsychotic, experienced greater improvement in the primary clinical outcome (that is, symptoms or functioning). ${ }^{50,52}$ Three trials found no difference in the primary clinical outcome between patients on single and multiple antipsychotics. ${ }^{48,49,51}$ O ne trial reported better clinical outcomes for patients on a single antipsychotic. ${ }^{47}$ Four of the six trials reported comparatively greater side effects for patients on multiple antipsychotics, whereas two found no differences in side effects. ${ }^{47-49,52} O$ ne trial reported that risperidone augmentation of clozapine worsened verbal working memory, while this outcome improved in the group that remained on a single antipsychotic. ${ }^{47}$

The RC Ts had small sample sizes (16-68 patients), were relatively brief (lasting from 6 to 12 weeks), and focused on a narrow selection of antipsychotics. Five of the six trials examined antipsychotic augmentation of clozapine. ${ }^{47-50,52}$ In four trials, the 


\section{Table 1. Studies Comparing Multiple Antipsychotics to Antipsychotic M onotherapy Among Patients with Established Treatment Resistance to M onotherapy*}

\begin{tabular}{|c|c|c|c|c|}
\hline $\begin{array}{l}\text { Anil- } \\
\text { Yağcioğlu } \\
2005\end{array}$ & $\begin{array}{l}\text { Double blind (DB) RCT } \\
\text { comparing clozapine with } \\
\text { clozapine/risperidone } \\
\text { patients with } \\
\text { schizophrenia partially } \\
\text { responsive to clozapine } \\
\text { monotherapy }\end{array}$ & $\begin{array}{l}\text { Monotherapy led to greater improvement } \\
\text { in positive symptoms overall on PANSS } \\
(p=.02 ; \text { primary outcome). } \\
\text { Monotherapy led to greater improvement } \\
\text { in delusions. } \\
\text { No difference between groups in quality of } \\
\text { life or functioning }\end{array}$ & $\begin{array}{l}\text { Multiple antipsychotics } \\
\text { increased sedation }(p=.01) \text {. } \\
\text { Multiple antipsychotics } \\
\text { increased prolactin levels } \\
(p \leq .0001) \text {. } \\
\text { No increase in QTc with com- } \\
\text { bination }\end{array}$ & \\
\hline $\begin{array}{l}\text { Freudenreich }{ }^{48} \\
2007\end{array}$ & $\begin{array}{l}\text { DB RCT comparing cloza- } \\
\text { pine with clozapine/risperi- } \\
\text { done in patients with } \\
\text { stable residual symptoms } \\
\text { of schizophrenia }\end{array}$ & $\begin{array}{l}\text { No difference between groups in symptom } \\
\text { improvement on PANSS (primary out- } \\
\text { come) } \\
\text { Multiple antipsychotics led to greater } \\
\text { improvement in disorganized thought } \\
\text { subscale }(p=.047) \text {. }\end{array}$ & $\begin{array}{l}\text { Multiple antipsychotics } \\
\text { increased prolactin levels } \\
(p=.02) \text {. } \\
\text { Multiple antipsychotics led to } \\
\text { tachycardia (significant but no } \\
p \text { value given). }\end{array}$ & \\
\hline $\begin{array}{l}\text { Josiassen }^{50} \\
2005\end{array}$ & $\begin{array}{l}\text { DB RCT comparing cloza- } \\
\text { pine with clozapine/risperi- } \\
\text { done in patients with } \\
\text { schizophrenia and } \\
\text { schizoaffective disorder } \\
\text { unresponsive or partially } \\
\text { responsive to clozapine } \\
\text { monotherapy }\end{array}$ & $\begin{array}{l}\text { More patients responded on combination } \\
(p<.01 ; \text { primary outcome). } \\
\text { Both groups experienced a reduction of } \\
\text { symptoms on BPRS }(p<.0001) \text {. } \\
\text { Combination more effective at symptom } \\
\text { reduction than monotherapy }(p<.04) \text {. }\end{array}$ & $\begin{array}{l}\text { No difference in side effects } \\
\text { including weight, agranulocy- } \\
\text { tosis, and seizures }\end{array}$ & $\begin{array}{l}\text { Response defined as } \\
\geq 20 \% \text { decrease in } \\
\text { symptoms on BPRS }\end{array}$ \\
\hline $\begin{array}{l}\text { Agelink }^{53} \\
2004\end{array}$ & $\begin{array}{l}\text { Open-label, observational } \\
\text { study of amisulpride } \\
\text { added to clozapine for } \\
\text { psychosis } \\
\text { or schizoaffective disorder } \\
\text { unresponsive to clozapine } \\
\text { monotherapy }\end{array}$ & $\begin{array}{l}\text { Multiple antipsychotics led to greater } \\
\text { improvement in symptoms on BPRS } \\
(p<.05 ; \text { primary outcome }) \text {. }\end{array}$ & $\begin{array}{l}\text { No changes in ECG in either } \\
\text { group }\end{array}$ & \\
\hline
\end{tabular}




\section{Table 1. Studies Comparing Multiple Antipsychotics to Antipsychotic M onotherapy Among Patients with Established Treatment Resistance to M onotherapy* (continued)}

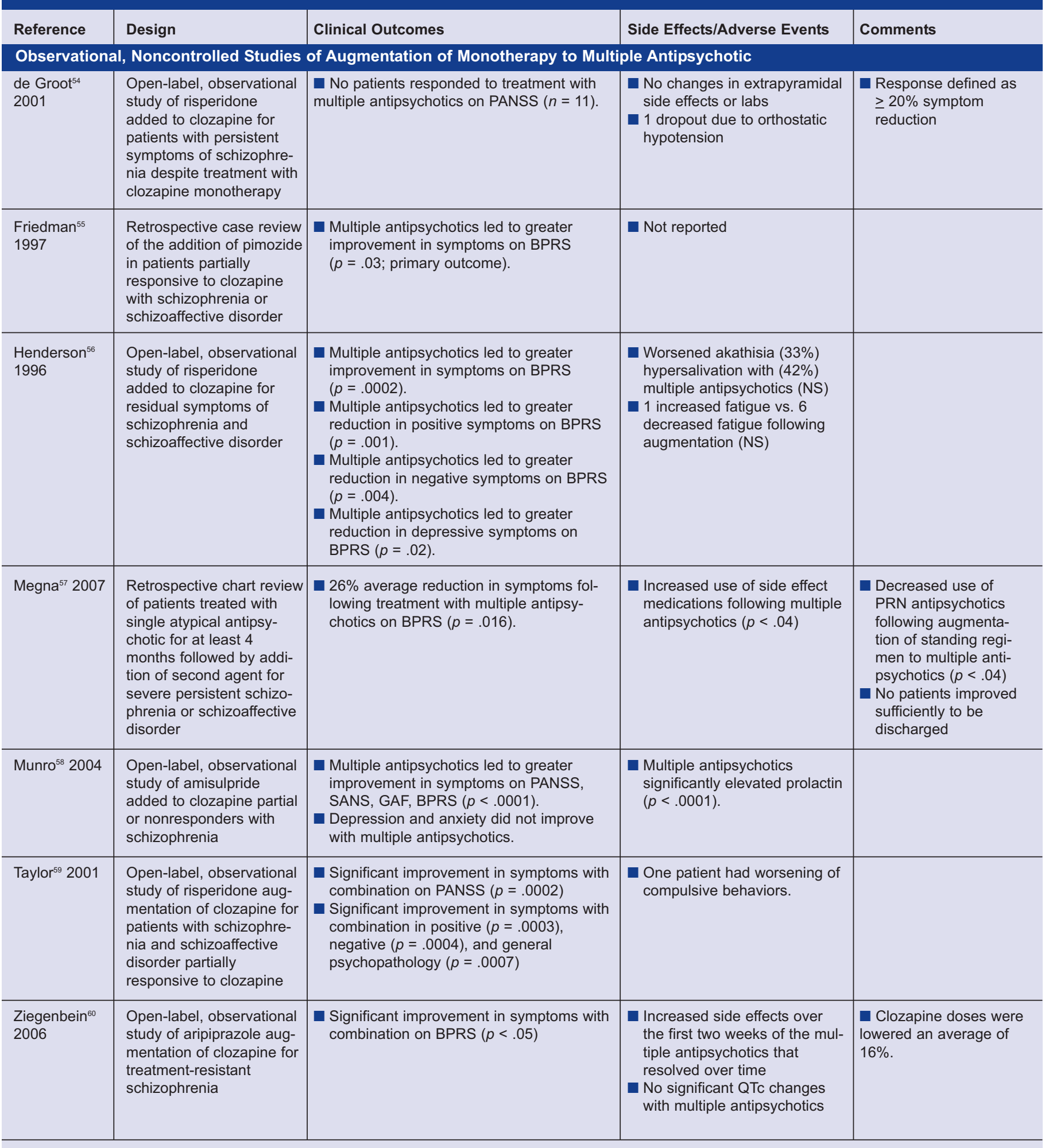




\section{Table 1. Studies C omparing Multiple Antipsychotics to Antipsychotic M onotherapy Among}

Patients with Established Treatment Resistance to Monotherapy* (continued)

\begin{tabular}{|c|c|c|c|c|}
\hline \multicolumn{5}{|c|}{ Observational, Noncontrolled Studies of Augmentation of Monotherapy to Multiple Antipsychotic } \\
\hline $\begin{array}{l}\text { Ziegenbein }^{61} \\
2005\end{array}$ & $\begin{array}{l}\text { Open-label, observational } \\
\text { study of ziprasidone- } \\
\text { clozapine combination for } \\
\text { treatment-resistant } \\
\text { schizophrenia }\end{array}$ & $\begin{array}{l}\text { Significant improvement in symptoms with } \\
\text { combination on BPRS }(p=.013)\end{array}$ & $\begin{array}{l}\text { Side effects reported with mul- } \\
\text { tiple antipsychotics: } 2 \text { patients } \\
\text { each with increased sedation, } \\
\text { decreased sedation, hyper- } \\
\text { salivation, weight loss; } 1 \\
\text { patient each with increased } \\
\text { LFTs, tremor, EEG changes; } \\
\text { hypotension (all NS) }\end{array}$ & $\begin{array}{l}\text { Multiple antipsychotics } \\
\text { accompanied by } 18 \% \\
\text { reduced total daily } \\
\text { dose of clozapine }\end{array}$ \\
\hline
\end{tabular}

* PANSS, Positive and Negative Syndrome Scale; QTc, Q-T interval corrected for heart rate; BPRS, Brief Psychiatric Rating Scale; HAMD, Hamilton Depression (Scale); SAPS, Scale for the Assessment of Positive Symptoms; SANS, Scale for the Assessment of Negative Symptoms; ECG, electrocardiogram; NS, not significant; PRN, as needed; GAF, Global Assessment of Functioning (Scale); LFTs, liver function tests; EEG, electroencephalogram.

augmenting agent was risperidone, ${ }^{47-50}$ whereas in the fifth it was sulpiride ${ }^{52}$, an SG A not available in the U nited States. The sixth trial compared the combination of olanzapine and sulpiride with olanzapine monotherapy. ${ }^{51}$

We identified nine noncontrolled observational trials comparing antipsychotic polypharmacy to monotherapy in samples with established treatment resistance to trials of a single antipsychotic (Table 1). ${ }^{53-61}$ All studies were of patients with schizophrenia or schizoaffective disorder. Eight of the trials reported significant improvement in reduced symptoms with the addition of a second antipsychotic. ${ }^{53,55-61}$ Of the eight studies that examined side effects, four reported no change with the addition of a concurrent antipsychotic. ${ }^{53,54,59,60}$ Three studies reported increased side effects with the addition of another antipsychotic, $^{56-58}$ whereas one study reported a decrease in sedation. ${ }^{56}$

The observational studies also had small sample sizes (7-28 patients), and most of them were longer than the RCTs (1-9 months). As with the more rigorous trials, these studies focused on a narrow selection of antipsychotics. Of the nine trials, eight involved clozapine augmentation. ${ }^{53-56,58-61}$ Clozapine was augmented with risperidone in three studies,;4,5,59 amisulpride (a second-generation drug not available in the United States) in two trials; ${ }^{53,58}$ and pimozide ${ }^{55}$, aripiprazole, ${ }^{60}$ and ziprasidone ${ }^{61}$ each in one trial. The ninth trial reported on the nonspecific use of two SGAs in combination. ${ }^{57}$

\section{Sam ples W ith Out Established T Reatment} RESISTANCE TO ANTIPSYCHOTIC M ONOTHERAPY

We identified three RCTs that compared antipsychotic polypharmacy to monotherapy in samples without established treatment resistance to a single antipsychotic (Table 2, pages 576-578). ${ }^{60-62}$ All three studies were of patients with schizophrenia or schizoaffective disorder. None of the three trials found clinical outcomes from multiple antipsychotics to be significantly better than outcomes from a single antipsychotic. ${ }^{62-64}$ of the two trials that studied side effects, on ${ }^{62}$ reported worsened constipation and sedation in the multipleantipsychotic group, while the other ${ }^{64}$ reported reduced prolactin levels with aripiprazole augmentation.

We identified six nonrandomized controlled trials that compared antipsychotic polypharmacy to monotherapy in samples without established treatment resistance to a single antipsychotic (Table 2). ${ }^{65-70}$ Three of the trials studied samples with mixed diagnoses, ${ }^{65-67}$ whereas three studied schizophrenia or schizoaffective disorder. ${ }^{68-70}$ of the four trials reporting clinical outcomes, three reported no improvement, ${ }^{65,66,69}$ while the fourth study reported mixed results. ${ }^{70}$ Multiple antipsychotics were more beneficial than monotherapy at lower dosages but no better than monotherapy at higher dosages. ${ }^{70}$ Four of the six studies reported on side effects- three reported a trend toward greater side effects with multiple antipsychotics ${ }^{66,68,70}$ and the fourth reported significantly greater side effects in this group. ${ }^{68}$

We identified six noncontrolled observational studies that examined the relationship between antipsychotic polypharmacy and clinical outcomes in samples without documented treatment resistance to monotherapy (Table 2). ${ }^{11-76} \mathrm{O}$ ne study did not report on clinical outcomes..$^{71}$ Three of the studies evaluated the addition of a second antipsychotic to an existing antipsychotic ${ }^{72,74,75}$; two studies found no improvement in 
Table 2. Studies Comparing Multiple Antipsychotics to Antipsychotic M onotherapy Among Patients W ithout Established Treatment Resistance to M onotherapy

\begin{tabular}{|c|c|c|c|c|}
\hline Reference & Design & Clinical Outcomes & Side Effects/Adverse Events & Comments \\
\hline \multicolumn{5}{|c|}{ Randomized Controlled Trials (RCTs) Comparing Multiple Antipsychotics to Monotherapy } \\
\hline Potkin ${ }^{62} 2002$ & $\begin{array}{l}\text { An open-label RCT com- } \\
\text { paring quetiapine alone in } \\
\text { initial period with quetiap- } \\
\text { ine combination (randomly } \\
\text { assigned to haloperidol, } \\
\text { risperidone, or thiorida- } \\
\text { zine) for patients in } \\
\text { remission from psychotic } \\
\text { symptoms in schizophre- } \\
\text { nia, bipolar, or schizoaf- } \\
\text { fective disorder }\end{array}$ & $\begin{array}{l}\text { No significant differences in symptom } \\
\text { change between multiple-antipsychotic } \\
\text { groups and monotherapy group on BPRS } \\
\text { or CGI }\end{array}$ & $\begin{array}{l}\text { Risperidone }+ \text { quetiapine } \\
\text { increased sleepiness } \\
(p<.05) \text {. } \\
\text { Haloperidol + quetiapine } \\
\text { increased constipation } \\
(p<.05) \text {. }\end{array}$ & $\begin{array}{l}\text { Study's primary intent } \\
\text { was to assess for } \\
\text { drug interactions; also } \\
\text { examined clinical out- } \\
\text { comes and other side } \\
\text { effects. } \\
\text { Short study period: } \\
\text { initial monotherapy } \\
\text { phase of } \geq 7 \text { days, } \\
\text { followed by combina- } \\
\text { tion phase of } 8.5 \text { days }\end{array}$ \\
\hline Potter $^{63} 1989$ & $\begin{array}{l}\text { RCT of chlorpromazine } \\
\text { alone, clozapine alone, or } \\
\text { chlorpromazine + clozap- } \\
\text { ine for schizophrenia }\end{array}$ & $\begin{array}{l}\text { Multiple antipsychotics were no better than } \\
\text { monotherapy with clozapine in reducing } \\
\text { overall symptom levels on BPRS. }\end{array}$ & Not reported & $\begin{array}{l}\text { Clozapine with or } \\
\text { without chlorpro- } \\
\text { mazine was more } \\
\text { effective in reducing } \\
\text { selected positive } \\
\text { symptoms than chlor- } \\
\text { promazine alone. }\end{array}$ \\
\hline Shim ${ }^{64} 2007$ & $\begin{array}{l}\text { Double blind (DB) RCT of } \\
\text { augmentation of haloperi- } \\
\text { dol with aripiprazole for } \\
\text { patients with hyperpro- } \\
\text { lactinemia on haloperidol } \\
\text { for clinically stable schizo- } \\
\text { phrenia. }\end{array}$ & $\begin{array}{l}\text { No significant change in symptoms } \\
\text { observed with augmentation on BPRS }\end{array}$ & $\begin{array}{l}\text { Prolactin normalized on } \\
\text { haloperidol-aripiprazole } \\
(p<.0001 \text {; primary outcome) } \\
\text { Dry mouth (31\%), headache } \\
(23 \%) \text {, insomnia ( } 42 \%) \text {, and } \\
\text { weakness occurred more fre- } \\
\text { quently in augmentation group } \\
\text { (NS). } \\
\text { EPS improvement in } 20 \% \text { of } \\
\text { augmented patients (NS) } \\
2 \text { patients withdrew because } \\
\text { of insomnia, irritability, and } \\
\text { anxiety on combination. }\end{array}$ & $\begin{array}{l}\text { Study's primary intent } \\
\text { was to assess poten- } \\
\text { tial of augmentation to } \\
\text { lower prolactin levels; } \\
\text { also examined clinical } \\
\text { outcomes and other } \\
\text { side effects. }\end{array}$ \\
\hline \multicolumn{5}{|c|}{ Nonrandomized Controlled Studies Comparing Multiple Antipsychotics to Monotherapy } \\
\hline
\end{tabular}

(continued on page 577) 
Table 2. Studies Comparing Multiple Antipsychotics to Antipsychotic M onotherapy Among Patients Without Established Treatment Resistance to Monotherapy (continued)

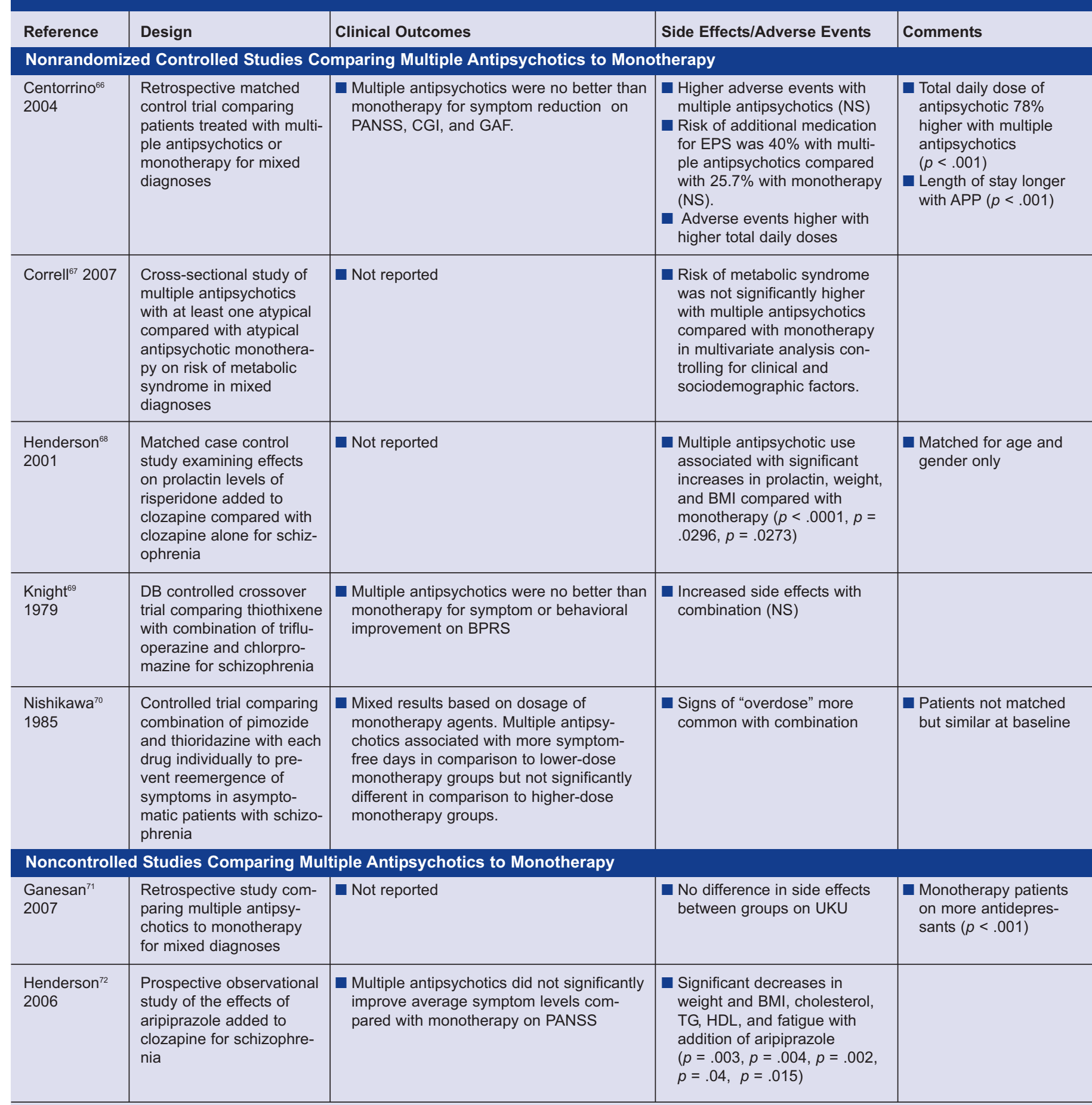


Table 2. Studies Comparing Multiple Antipsychotics to Antipsychotic M onotherapy Among Patients Without Established Treatment Resistance to M onotherapy (continued)

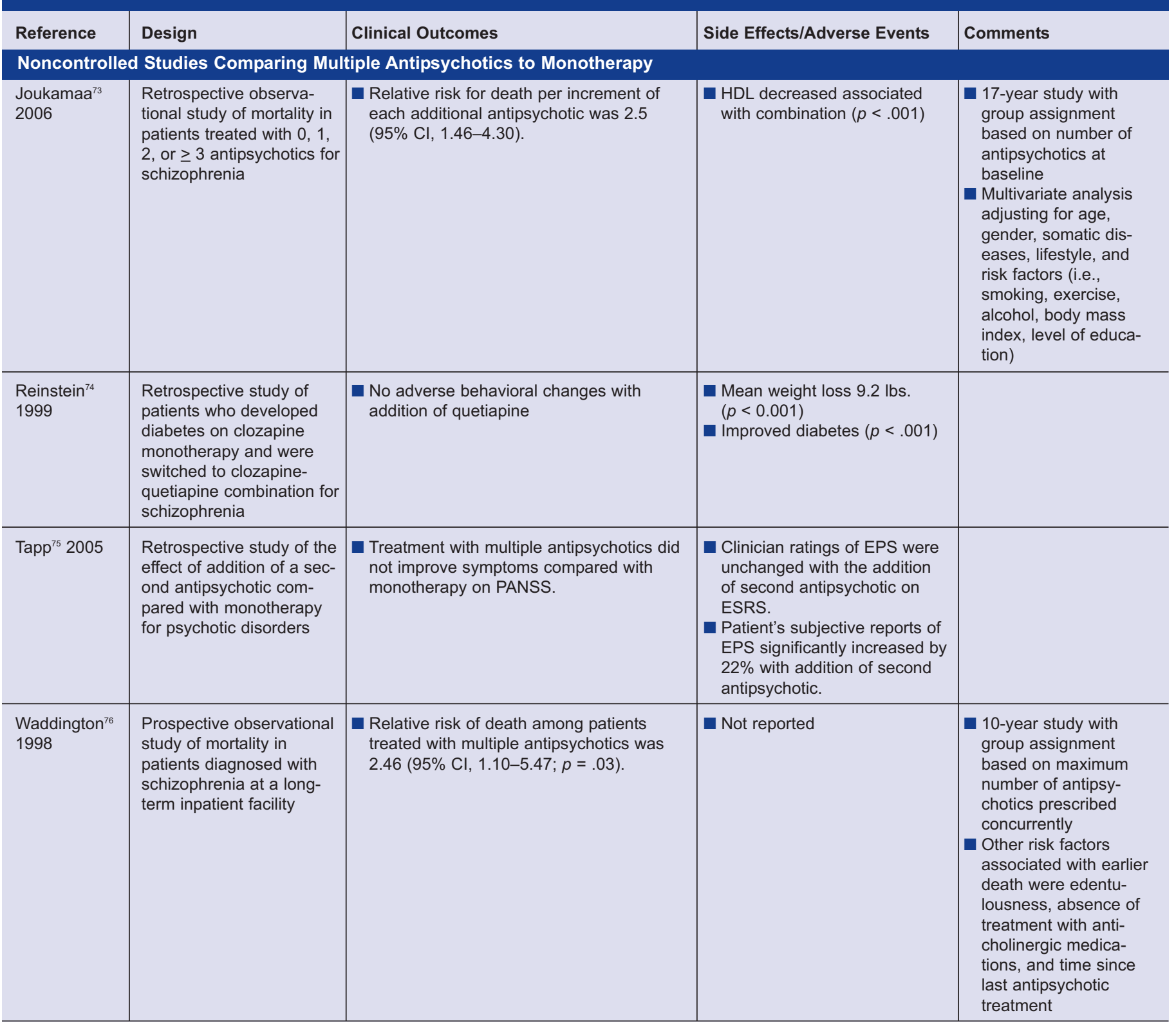

* BPRS, Brief Psychiatric Rating Scale; CGI, Clinical Global Impression (Scale); EPS, extrapyramidal side affects; PANSS, Positive and Negative Syndrome Scale; GAF, Global Assessment of Functioning (Scale); BMI, body mass index; NS, not significant; UKU, The Udvalg for Kliniske Undersøgelser Side Effect Rating Scale; TG, triglycerides; HDL, high-density lipoprotein; Cl, confidence interval; ESRS, Extrapyramidal Symptoms Rating Scale.

symptoms, ${ }^{72,75}$ while one study reported no clinical effects. ${ }^{74}$ The remaining two studies had a different design, using regression analysis to assess the association between antipsychotic polypharmacy and premature death in patients with schizophrenia. ${ }^{73,76}$ Controlling for multiple sociodemographic and clinical factors, both studies found that use of two or more antipsychotics was associated with increased mortality. Five of the six studies reported on side effects. ${ }^{71-75}$ Two found that antipsychotic polypharmacy was associated with improved side effects, ${ }^{72,74}$ one with worsening, ${ }_{13}^{73}$ and the other with no difference. ${ }^{71,75}$

\section{Discussion}

D espite the high prevalence of antipsychotic polypharmacy, the 


\section{The Joint Commission's Hospital-Based Inpatient Psychiatric Service (HBIPS) Core Measures on Antipsychotic Polypharmacy}

\author{
1. Patients discharged on multiple antipsychotic medications \\ Denominator: Psychiatric inpatients discharged on one or more routinely scheduled antipsychotic \\ medications \\ Standing antipsychotics only \\ Planned discharges only \\ Numerator: Inpatients from the denominator who are discharged on two or more routinely \\ scheduled antipsychotic medications \\ 2. Patients discharged on multiple antipsychotic medications with appropriate justification \\ Denominator: Psychiatric inpatients discharged on two or more routinely scheduled antipsychotic \\ medications \\ Standing antipsychotics only \\ Planned discharges only \\ Numerator: Inpatients from the denominator discharged on two or more routinely scheduled \\ antipsychotic medications with appropriate justification, i.e., is there documentation in \\ the medical record of: \\ A history of three or more failed trials of monotherapy \\ Recommended plan to taper to monotherapy in continuing care plan \\ Clozapine augmentation
}

effects were limited in these studies but generally suggested that polypharmacy was associated with greater side effects.

In both groups, studies with more rigorous designs (that is, RCTs and other controlled studies) were more likely to show a lack of benefit from polypharmacy than studies with less rigorous designs. A limitation of these trials is that few studies confirmed patient adherence, either through blood levels or other means, with antipsychotic medications as prescribed.

In light of concern over the high prevalence of antipsychotic polypharmacy and the evidence from research studies, the Joint Commission has adopted two measures of antipsychotic polypharmacy as part of its recently issued core measure set for H ospital-Based Inpatient Psychiatric Services (H BIPS; Figure 1 , left). ${ }^{36}$ The first measure reports data in support of this practice are limited and narrowly focused. Among patients with established treatment resistance to previous trials of antipsychotic monotherapy, RCTs showed mixed results in clinical outcomes and generally greater side effects with multiple antipsychotics. Positive clinical findings were limited to studies that either included SG As unavailable in the United States or augmentation of clozapine, a unique antipsychotic with relative low utilization in the U nited States because of risks of agranulocytosis and need for close monitoring. .2-64 $^{62}$ The findings support wider use of clozapine, which practice guidelines recommend be tried before use of multiple antipsychotics. ${ }^{42-44}$ The findings also emphasize the need for further research on augmentation strategies using a wider range of antipsychotics.

On the other hand, among patients who do not meet the guideline recommendation of multiple unsuccessful trials of a single antipsychotic before the addition of a second, research studies do not support use of multiple antipsychotics. Three RCTs and five of six nonrandomized controlled trials found multiple antipsychotics to be no better than a single antipsychotic in improving primary clinical outcomes. The sixth controlled trial showed mixed results based on dose. $D$ ata on side hospitals' rate of patients discharged on two or more routinely scheduled antipsychotics. The second examines whether patients discharged on two or more antipsychotics have a documented, clinically appropriate justification for use of multiple agents.

In developing these and the five other H BIPS measures, the Joint Commission brought together a technical advisory panel ${ }^{36}$ representing a range of stakeholder perspectives. Part of the panel's role was to identify clinically appropriate justifications for multiple antipsychotics. The first two justifications come directly from practice guidelines and research studies: a history of multiple unsuccessful trials of monotherapy and augmentation of clozapine. The third justification reflects a reality of contemporary inpatient psychiatric care. In this era of short inpatient stays, the primary focus of hospitalization for acute episodes of psychotic conditions is stabilization, followed by transfer to a less intensive level of care for ongoing treatment. Under these circumstances, inpatient clinicians often add a new antipsychotic to an existing one but discharge the patient before the original antipsychotic can be safely tapered off. Among patients who have not had multiple trials of monotherapy, discontinuation of the initial agent can be completed by 


\section{The Joint Commission Journal on Quality and Patient Safety}

the provider of the next level of care. Thus, the third clinically appropriate rationale built into the measure is as follows: documented communication to the patient's after-care clinician of a continuing care plan recommending a taper to monotherapy.

The advisory panel considered other reasons that psychiatrists may have for prescribing multiple antipsychotics, including those proposed in Joint Commission focus groups and in response to calls for public comment. No other rationales were adequately supported by research evidence or by consensus judgments of expert clinicians.

Reducing unnecessary antipsychotic polypharmacy poses several challenges to inpatient psychiatric units and the hospital systems that support them. Documentation of a patient's past antipsychotic trials often is missing or incomplete, or is spread over several volumes of old medical records. Improving performance will likely require that inpatient units adopt systematic processes to maintain accessible, up-to-date information on previous antipsychotic treatment-including documentation of past drug trials and their duration, clinical response, and side effects. Another challenge is that communication between inpatient and outpatient clinicians following a hospital stay varies widely. ${ }^{77}$ Although discharge summaries are routinely completed at or near time of discharge, they often are not sent to providers at the next level of care in a timely fashion. Patients with psychotic illnesses can be a limited conduit for providing treatment plan information and may or may not have family members, case managers, or others who serve this role. Improving communication between hospital and providers of the next level of care is the primary goal of another H BIPS measure and is an important component of avoiding unnecessary antipsychotic polypharmacy by communicating the inpatient psychiatrist's intentions regarding antipsychotic medications.

A final challenge is not limited to this quality measure but is common to all Q I activities based on process measures that can be influenced by multiple providers, clinical settings, and patients themselves. W ill inpatient clinicians and managers be able to focus on and act on that part of unnecessary antipsychotic polypharmacy that is under their control, as opposed to that which is determined by others? It is unlikely that even the most evidence-based, conscientious, and effective inpatient units will achieve perfect performance on even the second measure, any more than adult inpatient units can truly reduce restraint rates to zero if they admit agitated, assaultive psychotic patients. However, just as many facilities, including state mental health systems, have achieved significant decreases in physical restraint use through education, training, innovative procedures, and enhanced communication, ${ }^{78,79}$ it is likely that inpatient teams can also reduce the rate of unnecessary antipsychotic polypharmacy.

Several interventions to reduce multiple antipsychotic use have achieved promising results. For example, Suzuki et al. converted 22 of 44 patients (initially treated with an average of three antipsychotics) to a single antipsychotic. Of the 22 patients on monotherapy, 8 showed symptomatic improvement, whereas symptom levels for the other 14 were unchanged. ${ }^{80} D$ issemination of treatment al gorithms alone has not been found to be effective, ${ }^{16}$ but Chong et al. reported that combining treatment algorithm implementation with periodic audits of algorithm compliance significantly decreased antipsychotic polypharmacy. ${ }^{19}$ Thompson et al. achieved a modest reduction using a multifaceted approach combining group education, academic detailing, and chart reminders. The literature on interventions to reduce antipsychotic polypharmacy is extensive; review of these studies would be timely. In addition, rigorously designed trials evaluating current best practices would be of value to inpatient clinicians and managers.

W hile we have chosen to focus this review on the clinical impact of antipsychotic polypharmacy, other authors have described the financial impact of this practice. ${ }^{81,82}$ Financial concerns have led many payers to implement formulary restrictions on antipsychotic use. These restrictions are often more sweepingly restrictive than evidence-based guideline recommendations for multiple antipsychotic use. ${ }^{83}$

\section{Conclusion}

Research evidence only supports the use of antipsychotic polypharmacy in treatment-resistant patients, primarily when augmenting clozapine with an SG A. Treatment guidelines recommend not resorting to antipsychotic polypharmacy until after multiple failed trials of antipsychotic monotherapy, including clozapine. Ultimately, the value of assessing and reducing rates of antipsychotic polypharmacy requires the demonstration of improved clinical outcomes and/or reduced side effects after converting patients from multiple, unjustified antipsychotics to monotherapy. Ideally, this should be done through RCTs that provide definitive evidence of causality. H owever, the implementation of a nationwide quality measure offers an excellent, naturalistic opportunity to validate the measure by examining the association between improved performance and patient outcomes. Further research is also needed to identify the most effective (and cost-effective) methods for achieving improved performance. J 


\section{The Joint Commission Journal on Quality and Patient Safety}

Jessica L. Gören, Pharm.D., B.C.P.P., is Assistant Professor, Pharmacy Practice, University of Rhode Island, Kingston, Rhode Island; Clinical Pharmacist Specialist, Cambridge Health Alliance, Somerville, Massachusetts; and Instructor in Psychiatry, Harvard Medical School, Boston. Joseph J. Parks, M.D., is Chief Clinical Officer, Missouri Department of Mental Health, Columbia, Missouri, and Clinical Assistant Professor of Psychiatry, Missouri Institute of Mental Health and University of Missouri, Columbia. Frank A. Ghinassi, Ph.D., is Vice President, Quality and Performance Improvement, Western Psychiatric Institute and Clinic, University of Pittsburgh Medical Center, Pittsburgh, and Assistant Professor in Psychiatry, University of Pittsburgh School of Medicine. Celeste G. Milton, M.P.H., B.S.N., R.N., is Associate Project Director, Center for Performance Measurement, Department of Quality Measurement, Division of Quality Measurement and Research, The Joint Commission, Oakbrook Terrace, Illinois. John M. Oldham, M.D., is Senior Vice President and Chief of Staff, the Menninger Clinic, Topeka, Kansas, and Professor and Executive Vice Chair, Menninger Department of Psychiatry and Behavioral Sciences, Baylor College of Medicine, Houston, Texas. Pablo Hernandez, M.D., is Administrator, the GEO Group, Inc., South Florida Evaluation and Treatment Center-Annex, Miami. Jeffrey Chan is Research Associate, Center for Quality Assessment and Improvement in Mental Health, Tufts University School of Medicine, Boston. Richard C. Hermann, M.D., M.S., is Associate Professor of Medicine and Psychiatry and Director, Center for Quality Assessment and Improvement in Mental Health, Tufts University School of Medicine, Boston; Associate Director, Center for Organization, Leadership and Management Research, VA Boston Healthcare System, Boston; and a member of The Joint Commission Journal on Quality and Patient Safety's Editorial Advisory Board. Please address requests for reprints to Jessica L. Gören, jgoren@challiance.org.

\section{References}

1. Lieberman J.A., et al.: Effectiveness of antipsychotic drugs in patients with chronic schizophrenia. N EngJ M ed 353:1209-1223, Sep. 26, 2005.

2. Zyprexa [package insert]. Indianapolis, IN : Eli Lilly and Company, 2007.

3. Risperdal [package insert]. T itusville, N J: Janssen LP, 2007.

4. Seroquel [package insert]. Wilmington, D E: AstraZeneca Pharmaceuticals, 2008.

5. Abilify [package insert]. Princeton, N J: Bristol M yers Squibb, 2007.

6. Symbyax [package insert]. Indianapolis, IN : Eli Lilly and Company, 2008.

7. Centorrino $F_{\text {., }}$ et al.: U se of combination antipsychotics: M CLean H ospital inpatients, 2002. H um Psychopharmacol 20:485-492, 0 ct. 20, 2005.

8. Jaffe A.B., et al.: Antipsychotic medication co-prescribing in a large state hospital system. Pharmacoepidemiol D rug Saf 12:41-48, Jan.-Feb. 2003.

9. Centorrino E., et al.: Hospital use of antipsychotic drugs: Polytherapy. Compr Psychiatry 49:65-69, Jan.-Feb. 2008.

10. Procyshyn R.M ., et al.: Antipsychotic polypharmacy: A survey of discharge prescriptions from a tertiary care psychiatric institution. Can J Psychiatry 46:334-339, M ay 2001.

11. Centorrino F., et al.: Antipsychotic drug use, M cLean H ospital, 2002. H um P sychopharmacol 20:355-359, 0 ct. 2005.

12. Grohmann R., et al.: Psychotropic drug use in psychiatric inpatients: recent trends and changes over time--Data from the AM SP study. Pharmacopsychiatry 37(suppl. 1):S27-S38, M ar. 2004.

13. Covell N.H., et al.: Antipsychotic prescribing practices in Connecticut's public mental health system: Rates of changing medication prescribing styles. Schizophr Bull 28(1):17-29, 2002.
14. Ganguly R., et al.: Prevalence, trends, and factors associated with antipsychotic polypharmacy among M edicaid-eligible schizophrenia patients, 1998-2000. J Clin Psychiatry 65:1377-1388, Oct. 2004.

15. Gilmer T.P., et al.: Antipsychotic polypharmacy trends among M edicaid beneficiaries with schizophrenia in San D iego County, 1999-2004. Psychiatr Serv 59:1007-1010, Jul. 2007.

16. Thompson A., et al.: The DEBIT trial: An intervention to reduce antipsychotic polypharmacy prescribing in adult psychiatry wards- A cluster randomized controlled trial. Psychol M ed 10:1-11, M ay 2008.

17. Edlinger $M$., et al.: T rends in the pharmacologic treatment of patients with schizophrenia over a 12 year observation period. Schizophr Res 77(1):25-34, 2005.

18. Rittmannsberger $H_{\text {., }}$ et al.: Polypharmacy in psychiatric treatment: Patterns of psychotropic drug use in Austrian psychiatric clinics. Eur Psychiatry 14:33-40, M ar. 1999.

19. Chong S.A., et al.: Reducing polypharmacy through the introduction of a treatment algorithm: $U$ se of a treatment algorithm on the impact of polypharmacy. Ann Acad M ed Singapore 35:457-460, Jul. 2006.

20. Biancosino B., et al.: D eterminants of antipsychotic polypharmacy in psychiatric inpatients: A prospective study. Int Clin Psychopharmacol 20:305-309, N ov. 2005.

21. Procyshyn R.M., et al.: Patterns of antipsychotic utilization in a tertiary care psychiatric institute. Pharmacopsychiatry 37:12-17, Jan. 2004.

22. M cCue R.E., et al.: Polypharmacy in patients with schizophrenia. J Clin Psychiatry 64:984-989, Sep. 2003.

23. H amann J., et al.: Antipsychotic prescribing patterns in Germany: A retrospective analysis using a large outpatient database. Int Clin P sychopharmacol 18:237-242, Jul. 2003.

24. H umberstone $V_{\text {., }}$ et al.: An audit of outpatient antipsychotic usage in three health sectors of Auckland, N ew Zealand. Aust N Z J Psychiatry 38:240-245, Apr. 2004.

25. Kreyenbuhl J., et al.: Long-term combination antipsychotic treatment in VA patients with schizophrenia. Schizophr Res 84:90-99, M ay 2006.

26. Tapp A., et al.: Combination antipsychotic treatment in clinical practice. Psychiatr Serv 54:55-59, Jan. 2003.

27. T empier R.P., et al.: Conventional, atypical, and combination antipsychotic prescriptions: A 2 year comparison. J Clin Psychiatry 64:673-679, Jun. 2003.

28. Weissman E.M.: Antipsychotic prescribing practices in the Veteran $\mathrm{H}$ ealthcare Administration- $\mathrm{N}$ ew York metropolitan region. Schizophr Bull 28(1):31-42, 2002.

29. Schumacher J.E., et al.: M ultiple antipsychotic medication prescribing patterns. Ann Pharmacother 37:951-955, Jul.-Aug. 2003.

30. Taylor D., et al.: Co-prescribing of atypical and typical antipsychotics-Prescribing sequence and documented outcome. Psychol Bull 26:170-172, M ay 2002.

31. N ing A., et al.: Pharmacy costs: Finding a role for quality. Psychiatr Serv 56:909-911, Aug. 2005.

32. Stahl S.M ., et al.: H igh-cost use of second generation antipsychotics under California's M edicaid Program. Psychiatr Serv 57:127-129, Jan. 2006.

33. Barbui $C_{\text {., }}$ et al.: Persistence with polypharmacy and excessive dosing in patients with schizophrenia treated in 4 European countries. Int Clin Psychopharmacol 21:355-362, N ov. 2006.

34. Sabin J.E., et al.: I mproving psychiatric drug benefit management: Lessons from M assachusetts. Psychiatr Serv 54:949-951, Jul. 2003.

35. $\mathrm{N}$ ational Association of State $\mathrm{M}$ ental $\mathrm{H}$ ealth Program Directors Research Institute, Inc. (NRI): NRI Projects: Behavioral Healthcare Performance M easurement System. http://www.nri-inc.org/projects/BH PM S/morebhpms. cfm (last accessed Aug. 21, 2008).

36. The Joint Commission: Specification $M$ anual for $\mathrm{N}$ ational Quality $M$ easures- $H$ ospital-B ased Inpatient P sychiatric Services P sychiatric $C$ ore M easure Set (Version 2.0a), Jul. 2008. http://www.jointcommission.org/ PerformanceM easurement/PerformanceM easurement/H ospital +B ased + 


\section{The Joint Commission Journal on Quality and Patient Safety}

Inpatient+Psychiatric+Services.htm (last accessed Aug. 20, 2008).

37. D iaz E., et al.: Adherence to conventional and atypical antipsychotics after hospital discharge. J Clin Psychiatry 65:345-360, M ar. 2004.

38. Patel M.X., et al.: M edication adherence: Predictive factors and enhancement strategies. Psychiatry 6:357-361, Sep. 2007.

39. Sabin J.E., et al.: Public-sector managed behavioral health care: II. Contracting for M edicaid services- The M assachusetts experience. Psychiatr Serv 50:39-41, Jan. 1999.

40. Sabin J.E., et al.: I mproving psychiatric drug benefit management: III. The VA's approach to atypical antipsychotics. Psychiatr Serv 55:22-25, Jan. 2004.

41. H ermann R.C.: I mproving M ental H ealthcare: A Guide to M easurementBased Quality Improvement. Washington, DC: American Psychiatric Publishing, Inc., 2005.

42. American Psychiatric Association: Practice guideline for the treatment of patients with schizophrenia. American Psychiatric Association. Am J Psychiatry 161(suppl. 2):1-56, Feb. 2004

43. M oore, et al.: The TM AP Schizophrenia Algorithms, 2006 update. J Clin Psychiatry 68:1751-1762, N ov. 2007.

44. $\mathrm{N}$ ational Institute for $\mathrm{H}$ ealth and Clinical Excellence: Schizophrenia: Core Interventionsin the Treatment and $\mathrm{M}$ anagement of Schizophrenia in Primary and Secondary Care. 2002. http://www.nice.org.uk/guidance/index.jsp? action $=$ bylD \& $r=$ true\& $0=10916$ (last accessed Feb. 2, 2008).

45. Stahl S.M., et al.: A critical review of atypical antipsychotic utilization: Comparing monotherapy with polypharmacy and augmentation. Curr M ed Chem 11:313-327, Feb. 2004

46. Tranulis $C$., et al.: Benefits and risks of antipsychotic polypharmacy: An evidence based review of the literature. D rug Saf 31(1):7-20, 2008.

47. Anil-Yagcioglu A., et al.: A double blind controlled study of adjunctive treatment with risperidone in schizophrenic patients partially responsive to clozapine: Efficacy and safety. J Clin Psychiatry 66:63-72, Jan. 2005.

48. Freudenreich 0 ., et al.: Risperidone augmentation for schizophrenia partially responsive to clozapine: A doubleblind, placebo-controlled trial. Schizophr Res 92:90-94, M ay 2007.

49. H orner W .G ., et al.: Clozapine alone versus clozapine and risperidone with refractory schizophrenia. N Engl J M ed 354:472-482, Feb. 2006.

50. Josiassen R.C., et al.: Clozapine augmentation with risperidone in the treatment of schizophrenia: A randomized, double blind, placebo controlled trial. Am J Psychiatry 162:130-136, Jan. 2005.

51. Kotler M ., et al.: Sulpiride augmentation of olanzapine in the management of treatment-resistant chronic schizophrenia: Evidence for improvement of mood symptomatology. Int Clin Psychopharmacol 19:23-26, Jan. 2004.

52. Shiloh R., et al.: Sulpiride augmentation in people with schizophrenia partially responsive to clozapine: $\mathrm{A}$ double-blind, placebo-controlled study. $\mathrm{Br}$ J Psychiatry 171:569-573, D ec. 1997.

53. Agelink M.W, et al.: C lozapine with amisulpride for refractory schizophrenia (letter). Am J Psychiatry 161:924-925, M ay 2004.

54. de Groot I.W., et al.: Addition of risperidone to clozapine therapy in chronically psychotic inpatients. J Clin Psychiatry 62:129-130, Feb. 2001.

55. Friedman J., et al.: Pimozide augmentation for the treatment of schizophrenic patients who are partially responsive to clozapine. Biol Psychiatry 42:522-523, Sep. 15, 1997.

56. H enderson D.C., G off D.C.: Risperidone as an adjunct to clozapine therapy in chronic schizophrenics. J Clin Psychiatry 57:395-397, Sep. 1996.

57. Megna J.L., et al.: A study of polypharmacy with second generation antipsychotics in patients with severe and persistent mental illness. J Psychiatr Pract 13:129-137, M ar. 2007.

58. M unro J., et al.: Amisulpride augmentation of clozapine: An open nonrandomized study in patients with schizophrenia partially responsive to clozapine. Acta Psychiatr Scand 110:292-298, 0 ct. 2004.

59. Taylor C.G., et al.: An open trial of risperidone augmentation of partial response to clozapine. Schizophr Res 48:155-158, M ar. 1, 2001.
60. Ziegenbein $M$., et al .: Aripiprazole augmentation of clozapine in treatment resistant schizophrenia. Clin D rug Invest 26(3):117-124, 2006.

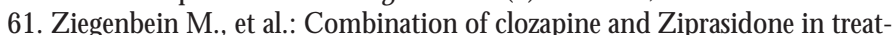
ment resistant schizophrenia: An open clinical study. Clin Neuropharmacol 28:220-224, Sep.- 0 ct. 2005.

62. Potkin S.G., et al.: The safety and pharmacokinetics of quetiapine when co-administered with haloperidol, risperidone or thioridazine. J Clin Psychopharmacol 22:121-130, Apr. 2002.

63. Potter W.Z., et al.: C lozapine in C hina: A review and preview of US/PCR collaboration. Psychopharmacology (Berl) 99(suppl.):S87-S91, 1989.

64. Shim J.C., et al.: Adjunctive treatment with a dopamine partial agonist, aripiprazole, for antipsychotic induced hyperprolactinemia: A placebo controlled trial. Am J Psychiatry 164:1404-1410, Sep. 2007.

65. Centorrino F., et al.: U se of combinations of antipsychotics: M CLean H ospital inpatients, 2002. H um P sychopharmacol 20:485-492, O ct. 2005.

66. Centorrino $F_{\text {., }}$ et al.: M ultiple vs. single antipsychotic agents for hospitalized psychiatric patients: Case-control study of risks versus benefits. Am J Psychiatry 161:700-706, Apr. 2004.

67. Correll C.U., et al.: D oes antipsychotic polypharmacy increase the risk of metabolic syndrome? Schizophr Res 89:91-100, Jan. 2007.

68. H enderson D.C., et al.: Risperidone added to clozapine: Impact on serum prolactin levels. J Clin Psychiatry 62:605-608, Aug. 2001

69. Knight R.G., et al.: A double blind comparison of thiothixene and a trifluoperazine/chlorpromazine composite in the treatment of chronic schizophrenia. N Z M ed J 89:302-304, Apr. 1979.

70. N ishikawa T., et al.: Prophylactic effects of neuroleptics in symptom free schizophrenics: Roles of dopaminergic and noradrenergic blockers. Biol Psychiatry 20:1161-1166, N ov. 1985.

71. Ganesan S., et al.: Antipsychotic polypharmacy does not increase the risk for side effects. Schizophr Res 98:323-324, Jan. 2008.

72. H enderson D.C., et al.: An exploratory open-label trial of aripiprazole as an adjuvant to clozapine therapy in chronic schizophrenia. Acta Psychiatr Scand 113:142-147, Feb. 2006.

73. Joukamaa M ., et al.: Schizophrenia, neuroleptic medication and mortality. Br J Psychiatry 188:122-127, Feb. 2006.

74. Reinstein M.J., et al.: Effect of clozapine-quetiapine combination therapy on weight and glycaemic control. Clin D rug Investig 18:99-104, Aug. 1999.

75. T app A.M., et al.: Antipsychotic polypharmacy: Do benefits justify the risks? Ann Pharmacother 39:1759-1760, O ct. 2005.

76. Waddington J.L., et al.: M ortality in schizophrenia: Antipsychotic polypharmacy and absence of adjunctive anticholinergics over the course of a 10-year prospective study. Br J Psychiatry 173:325-329, 0 ct. 1998.

77. Coleman E.A.: Falling through the cracks: Challenges and opportunities for improving transitional care for persons with continuous complex care needs. J Am Geriatr Soc 51:549-555, Apr. 2003.

78. Borckardt J.J., et al.: Enhancing patient safety in psychiatric settings. J Psychiatr Pract 13:355-361, N ov. 2007.

79. Sailas E., et al.: Restraint and seclusion in psychiatric inpatient wards. Curr O pin Psychiatry 8:555-559, Sep. 2005.

80. Suzuki T., et al.: Revising polypharmacy to a single antipsychotic regimen for patients with chronic schizophrenia. Int J Neuropsychopharmacol 7:133-142, Jun 2004.

81. Zhu B., et al.: Cost of antipsychotic polypharmacy in the treatment of schizophrenia. BM C Psychiatry 8:19, Apr. 4, 2008.

82. Valuck R.J., et al.: How expensive is antipsychotic polypharmacy? Experience from five US Medicaid programs. Curr Med Res 0 pin 23:2567-2576, Oct. 2007.

83. Semansky R.M., et al.: M edicaid Formulary Policies: Access to High-C ost M ental Health M edications. 1999. http://www.bazelon.org/issues/ medicaid/publications/formulary.htm (last accessed Aug. 21, 2008). 